\title{
PERAN HUMAS DALAM PENGEMBANGAN PENDIDIKAN TINGGI
}

\author{
MIFROHATUL MUSYARROFAH \\ Universitas Nurul Jadid, Paiton, Probolinggo \\ Email : mifroh17@gmail.com
}

\begin{abstract}
:
Currently the growth of the Internet indirectly also requires $P R$ practitioners to develop their communication media. Education is a very is important aspect of the implementation of human rights, the implementation of the right is done every country in order to achieve the national goals and goals of the country concerned. According to Onong, Public Relations or Public Relations is a two-way communication between the organization with its public or its audience, both internal and external public, in order to support the organization's management functions and objectives, by enhancing cooperation and the fulfillment of common interests, Education is a very important a aspect of the implementation of human rights, the implementation of the right is carried out by each country in order to achieve the national goals and objectives of the country concerned. Indonesia is one of the countries that recognize and protect human rights in education. While universities in Indonesia during the reform era still continue to experience a very complicated issue, with the problems raised a variety.
\end{abstract}

Keywords : the role of public relations, the development of higher education

\section{PENDAHULUAN}



ecara tidak langsung saat ini pertumbuhan Internet juga menuntut praktisi Humas untuk mengembangkan media komunikasi yang dimilikinya. Sebab, setidaknya ada 3 perubahan cara Public Relations bekerja sejak kehadiran Internet. Pertama, Internet mengubah cara orang memperoleh informasi dari organisasi. Kedua, komunikasi juga tidak lagi bersifat top-down atau yang bersumber dari satu pihak ke pihak lain, namun lebih dominan kepada komunikasi berjaringan. Ketiga, manfaatan Internet memunculkan adanya interaksi di antara organisasi dengan publiknya. Dalam pemanfaatan Internet ranah Public Relations ini Brian Solis dan Deirdre Breakenridge, menyebutnya sebagai Public Relations. ${ }^{1}$

Menurut Onong, Humas atau Public relations juga merupakan kegiatan komunikasi dua arah secara timbal-balik antara suatu organisasi dengan publik lainnya, publik internal maupun eksternal baik, dalam rangka mendukung fungsi dan tujuan manajemen organisasi tersebut, dengan meningkatkan pembinaan kerjasama dan memenuhi kepentingan bersama, yang dilandasi atas asas saling pengertian dan saling mempercaya. Kebanyakan organisasi besar memiliki staf humas tersendiri, dan juga dapat mengakibatkan kerja ganda. Dengan demikian itu

${ }^{1}$ Ani Soetjipto and others, 'OTONOMI DAN TATA KELOLA PERGURUAN TINGGI NEGERI Studi Kasus Di Universitas Indonesia, Universitas Negeri Jakarta, Dan Universitas Islam Negeri Syarif Hidayatullah Case Studies in the University of Indonesia, the Jakarta State University, and the Syari', Masyarakat \& Budaya, 16.2 (2014), 293-304. 
Humas haruslah memiliki manajemen komunikasi yang efektif dalam rangka memenuhi peran dan fungsinya sendiri dalam mendukung kegiatan perusahaan. ${ }^{2}$

John E. Marston membatasi public relations dalam dua batasan yaitu dalam arti umum dan public relations dalam arti khusus. Dalam arti umum dinyatakan bahwa: "Public Relations itu terencana, komunikasi persuasif di desain untuk mempengaruhi publik tertentu". Sementara dalam arti khusus dinyatakan bahwa: Public Relations adalah seni untuk perusahaan agar disukai dan dihormati oleh para karyawan, konsumen dan para penyalurnya. ${ }^{3}$

Pendidikan merupakan aspek sangat penting dari pelaksanaan hak-hak asasi manusia, penyelenggaraan hak tersebut dilakukan setiap negara demi mencapai cita-cita dan tujuan nasional negara yang bersangkutan. Indonesia termasuk salah satu negara yang mengakui dan melindungi hak asasi manusia di bidang pendidikan. ${ }^{4}$ Pendidikan merupakan ladang investasi terbesar dalam membangun dan membentuk manusia seutuhnya (insanul kamil). Sentuhan pendidikan diyakini mampu membentuk sumberdaya manusia (human resources) yang beradab dan berkualitas. $^{5}$

Perguruan tinggi di Indonesia pada masa reformasi masih terus mengalami persoalan yangsangat rumit.Persoalan yang mengemuka bermacam-macam, mulai dari campur tangan pemerintah (birokratisasi) dalam pengelolaan perguruan tinggi, biaya pendidikan yang tidak terjangkau oleh kaum miskin, kualitas riset dan publikasi yang memprihatinkan, sampai dengan masalah kultur budaya akademik yang belum sepenuhnya terbangun. ${ }^{6}$ Oleh diperlukan adanya profil perguruan tinggi yang mampu menampilkan sosok kualitas personal, sosial, dan profesionalisme dalam menjalankan tugasnya ${ }^{7}$

Hubungan antara penyelenggara pendidikan dan satuan pendidikan yang didirikan selama ini banyak mengindikasikan hubungan yang bersifat subordinatif (bukan koordinatif). Ini artinya satuan pendidikan lebih banyak yang diperlakukan sebagai bawahan. Ada juga yang bahkan diperlakukan laksana obyek hukum dengan kewenangan mengelola sangat minim. Meski ada juga yang walaupun merupakan bawahan tetapi satuan pendidikan merasa sangat terlindungi. Upaya menjadikan satuan pendidikan sebagai badan hukum adalah menjadikannya

2 Aswad Ishak, 'Peran Public Relations Dalam Komunikasi Organisasi', Komunikasi, 1.4 (2012), 373-80.

3 Choirul Fajri, 'PERAN HUMAS DALAM MENINGKATKAN LOYALITAS STAKEHOLDERS UNIVERSITAS AHMAD DAHLAN', Kajian IImu Komunikasi, 47.1 (2017), 97-108.

${ }^{4}$ Elvinaro Ardianto, 'Public Relations on the Net ':, Mediator, 2.1 (2001), 11-19.

5 Hasan Baharun, 'PENDIDIKAN ANAK DALAM KELUARGA; TELAAH EPISTEMOLOGIS', Pedagogik, 3.2 (2016), 96-107.

6 Ida Suryani Wijaya, 'Dinamika Komunikasi Organisasi Di Perguruan Tinggi', Dakwah Tabligh, 14.2 (2013), 203-15.

7 Hasan Baharun, Pengembangan Kurikulum: Teori Dan Praktik (Konsep, Prinsip, Model, Pendekatan Dan Langkah-Langkah Pengembangan Kurikulum PAl) (Yogyakarta: Cantrik Pustaka, 2017). 320 
subyek hukum yang memiliki hak dan kewenangan secara penuh (laksana manusia merdeka). ${ }^{8}$

Sebagaimana yang tertuang di dalam Undang- Undang No. 9/2009 tentang BHP, alasan pemerintah untuk membentuk BHP adalah: ${ }^{9}$

a. Bahwa untuk mewujudkan fungsi dan tujuan pendidikan nasional, diperlukan adanya otonomi dalam pengelolaan pendidikan formal dengan menerap- kan manajemen berbasis sekolah/madarasah padapendidikan anak usia dini jalur formal, pendidikan dasar dan menengah,serta otonomi perguruan tinggi pada pendidikan tinggi.

b. Bahwa dalam otonomi pengelolaan pendidikan formal dapat diwujudkan, jika penyelenggara dan satuan pendidikan formal berbentuk badan hukum pendidikan yang dapat berfungsi memberikan pelayanan yang adil dan bermutu kepada peserta didik, berprinsip nirlaba, dan juga dapat mengelola dana secara mandiri untuk memajukan satuan pendidikan.

c. Bahwa agar badan hukum pendidikan menjadi landasan hukum bagi penyelenggara dan satuan pendidikan dalam mengelola pendidikan formal, maka perlu diatur dengan undang-undang badan hukum pendidikan.

\section{Otonomi Perguruan tinggi}

Autonomy is defined as leaving the right of administration to the individuals or institutions. ${ }^{10}$ Dan University autonomy is described as universities' capability of setting their own goals, deciding on their administration, recruitting their staff and academics, having a block grant of budget, introducing new programmes freely (Estermann \& Nokkala, 2009). Consequently, if ministers, politicians, nongovernmet organizationss and other stakeholders interfere in universities' administration, it will damage university autonomy (Sufean \& Soaib, 2010). ${ }^{11}$

Otonomi Daerah pada tahun 2001 yang lalu mengakibatkan beberapa daerah berlomba-lomba untuk mendirikan perguruan tinggi Setelah diberlakukannya Undang-Undang tentang Otonomi. ${ }^{12}$ Pemberian dan berlakunya otonomi pendidikan di daerah memiliki nilai strategis bagi daerah untuk berkompetisi dalam upaya membangun dan memajukan daerah-daerah di seluruh nusantara, terutama yang

8 Ike Devi Sulistyaningtyas, 'Peran Strategis Public Relations Di Perguruan Tinggi', IImu Komunikasi, 4.2 (2007), 131-44.

9 Instr İbrahim and Serkan Ödemiş, 'AN EXPLORATORY STUDY ON UNIVERSITY AUTONOMY : A COMPARISON OF TURKEY AND SOME EUROPEAN UNION COUNTRIES', OF EDUCATION AND INSTRUCTIONAL STUDIES IN THE WORLD, 6.August (2016), 79-90.

10 Kurnia Setiyo Rini and others, 'Peran Humas Dalam Meningkatkan Citra Universitas Tribhuwana Tunggadewi', IImu Sosial Dan IImu Politik, 6.1 (2017), 34-37.

11 İbrahim and Ödemiş.

12 Lina Sinatra dan Ririn Darmastuti, 'KAJIAN PERAN PUBLIC RELATIONS DALAM MENINGKATKAN CITRA PERGURUAN TINGGI SWASTA DI JAWA TENGAH', IImiah SCRIPTURA, 2.2 (2008), 95-105. 
berkaitan langsung dengan sumber daya manusia dan alamnya da- lam mendobrak kebekuan dan stagnasi yang dialami dan melingkupi masyarakat selama ini. ${ }^{13}$

Masalah otonomi yang terkait dengan pendidikan menyangkut otonomi bidang akademik, tata organisasi, dan keuangan. Meski demikian, implementasinya di tingkat lapangan sangat bervariasi. Misalnya di perguruan tinggi negeri, ranah otonomi sebelum lahirnya BHMN dianggap tidak menyentuh ranah keuangan. ${ }^{14}$

Berpegang pada prinsip mendasar tentang otonomi dan meminjam model yang diajukan Trakman tentang tata kelola perguruan tinggi, dalam konteks Indonesia tulisan ini memaparkan studi kasus yang dilakukan di UI, UNJ, dan UIN Syarif Hidayatullah. Tata kelola yang menyangkut tiga dimensi, yaitu akademis, organisasi, dan keuangan, menjadi fokus dari pembahasan di tiga PTN tersebut. Selain itu, tulisan ini juga mendiskusikan bagaimana ketiga PTN tersebut memaknai otonomi PT dan melaksanakannya di masing-masing institusinya. ${ }^{15}$

\section{Fungsi Hubungan Masyarakat di Perguruan Tinggi}

Fungsi humas itu sendiri, yakni membangun fungsi manajemen serta mempertahankan hubungan baik dan bermanfaat antara organisasi dengan publik lain yang mempengaruhi kesuksesan atau kegagalan organisasi. ${ }^{16}$

Grunig, mendefinisikan public relations "management of communication between an organization and its publics" berdasarkan dari definisi diatas, Grunig menyatakan bahwa ada dua fungsi komunikasi yang berkaitan erat pada bidang public relations. ${ }^{17}$

1. Manajemen Komunikasi.

Pada hakikatnya, manajemen merupakan proses penggunaan sumber daya secara efektif untuk mencapai sasaran atau tujuan tertentu. ${ }^{18}$ Manajemen komunikasi pada hal ini artikan tidak hanya mengenai teknik atau strategi bagaimana untuk berkomunikasi atau kegiatan yang hanya meliputi programprogram seperti media relations dan publisitas. Manajemen komunikasi meliputi keseluruhan atas adanya kegiatan perencanaan, pelaksanaan dan evaluasi komunikasi pada organisasi tersebut, baik yang yang ditujukan pada publik ekstemal dan internal. Publik dalam hal ini juga disebut sebagai kelompok yang

13 Hasan Baharun, 'DESENTRALISASI DAN IMPLIKASINYA TERHADAP PENGEMBANGAN SISTEM PENDIDIKAN ISLAM', Jurnal At-Tajdid, 1.2 (2012). 242

14 M Kholid Fathoni, 'Badan Hukum Di Langit Pendidikan ( Studi Evaluasi Kebutuhan Satuan Pendidikan )', Pendidikan Dan Kebudayaan, 17.3 (2011), 299-305.

15 Novi Arista Nurcahyani, 'Pelaksanaan Hubungan Masyarakat Dalam Membangun Networking Di SMK Negeri 1 Surabaya', 1.1 (2015), 1-11.

16 Nur Ahid, 'Problem Pengelolaan Madrasah Aliyah Dan Solusinya', ISLAMICA, 4.2 (2010), 336-53.

17 Ratna Sari Tamher and M Najib Hm, 'PASAR INPRES KOTA TUAL The Roles of Public Relation in Crisis Management of the Tradisional Market Tual City Post Fire', Komunikasi KAREBA, 1.3 (2011), 271-82.

18 Hasan Baharun, 'Manajemen Kinerja Dalam Meningkatkan Competitive Advantage Pada Lembaga Pendidikan Islam', At-Tajdid: Jurnal IImu Tarbiyah, 5.2 (2016), 243-62. 
mempengaruhi kemampuan organisasi dalam mencapai tujuannya. Pada fungsi manajemen komunikasi ini, public relations juga berperan pada level managerial role yang memiliki peran pada perencana dan pengambilan keputusan dalam suatu strategi komunikasi yang dibuat.

2. Mengenai Komunikasi Organisasi.

Grunig juga mendefinisikan sebagai sistem komunikasi yang dikelola oleh organisasi, khususnya pada komunikasi antar setiap unit dalam organisasi, yang juga sengaja dirancang oleh para ahli komunikasi. Seperti setiap hal bagaimana pimpinan puncak, para manager dan pegawai biasa saling berkomunikasi satu sama yang lainnya dalam sebuah organisasi. Namun tidak menutup kemungkinan bahwa komunikasi organisasi tidak hanya mencakup pada area internal tetapi juga eksternal. Dalam melangsungkan kegiatan komunikasi tersebut tentunya juga para praktisi public relations membutuhkan suatu medium dalam menyebarluaskan informasi dari organisasi kepada publik lain dan sebaliknya untuk bisa dapat menjaring opini publik terhadap organisasi. Pada hal ini media masa menjadi salah satu medium atau saluran komunikasi yang diandalkan oleh para praktisi public relations terutama dalam hal yang berkaitan dengan tujuan publisitas.

Menurut Bertrand R. Canfield, dalam Rosady Ruslan, fungsi public relations adalah: a. It should serve the public interest (mengabdi pada kepentingan publik).

1. Maintain good commu-nication (memelihara komunikasi yang baik).

2. Stress good morals and manners (menitikberatkan moral dan perilaku yang baik). ${ }^{19}$

Menurut Cutlip dan Center, fungsi Public Relations. ${ }^{20}$

1. Hubungan internal. Hubungan internal merupakan bagian khusus Public Relations yang membangun dan yang mempertahankan hubungan baik dan saling bermanfaat antara manajer dan karyawan (staf) tempat organisasi mengantungkan kesuksesannya.

2. Publisitas. Publisitas merupakan sumber-sumber informasi yang sudah disediakan oleh Public Relations dan digunakan oleh media karena informasi itu memiliki nilai berita tersendiri. Metode Dalam penempatan pesan di media ini adalah pesan dimana media ini adalah metode yang tidak bisa dikontrol (uncontrolled) sebab sumber informasi ini tidak memberi bayaran kepada media untuk pemuatan informasi tersebut.

3. Advertising. Informasi yang digunakan oleh Public Relations ini untuk menjangkau audien yang lebih luas, bukan hanya untuk konsumen yang menjadi sasaran marketing, akan tetapi dimana informasi yang ditempatkan di media oleh sponsor tertentu yang jelas identitasnya yang membayar ruang dan

19 Rianti, 'KAJIAN YURIDIS TENTANG KEBERADAAN PERGURUAN TINGGI NEGERI BADAN HUKUM MILIK NEGARA DALAM UNDANG-UNDANG SISTEM PENDIDIKAN NASIONAL Rianti', IImu Hukum, 7.13 (2011), 1-10.

20 Rofiq Anwar, 'PERAN PRAKTISI PUBLIC RELATIONS DALAM ORGANISASI DI YOGYAKARTA', AN-NIDA, 7.1 (2015), 46-55. 
waktu penempatan informasinya tersebut. Ini adalah metode terkontrol dalam menempatkan pesan di media ini.

4. Penciptaan berita dan peristiwa yang bernilai berita diciptak Press agentry untuk menarik media masa dan mendapatkan perhatian publik. Hal ini Banyak praktisi Public Relations kadang-kadang menggunakan taktik press agentry untuk menarik perhatian media kepada kliennya, organisasinya, atau tujuannya. Tetapi Public Relations lebih dari sekedar press agentry.

5. Public affairs. Bagian khusus dari Public Relations yang membangun dan mempertahankan hubungan pemerintah dengan komunitas lokal dalam rangka memengaruhi kebijakan publik.

6. lobbying. Ini juga bagian khusus dari Public Relations yang berfungsi untuk menjalin dan juga memelihara hubungan dengan pemerintah terutama dengan tujuan memengaruhi penyusunan undang-undang dan regulasi yang sudah ditetapkan.

7. Manajemen isu. Proses proaktif dalam mengantisipasi, mengindentifikasi, mengevaluasi, dan merespon isu-isu kebijakan publik yang memengaruhi hubungan organisasi dengan publik mereka.

8. Hubungan investor. Bagian dari Public Relations ini juga terdapat didalam perusahaan korporat yang membangun dan menjaga hubungannya yang bermanfaat dan saling menguntungkan dengan shareholder dan pihak lain di dalam komunikasi keuangan dalam rangka memaksimalkan nilai pasar tertentu.

Cutlip \& Centre and Canfield juga menyatakan fungsi Public Relations adalah:

21

1. Menunjang aktivitas utama manajemen yang dalam mecapai tujuan bersama ( fungsi melekat pada manajemen lembagaataua organisasi).

2. Membina hubungan yang harmonis antara badan dan organisasi dengan publiknya yang merupakan khalaayak sasaran.

3. Mengidentifikasi segala suatu hal yang berkaitan dengan opini, persepsi dan tanggapan masyarakat terhadap lembaga atau organisasi yang sudah diwakilkan atau sebaliknya.

4. Melayani adanya keinginan publik dan memberikan sumbangan, saranprasarana kepada pimpinan manajemen demi tujuan dan manfaat bersama.

5. Menciptakan komunikasi dua arah timbal balik dan mengatur semua arus informasi, publikasi serta pesan dari badan atau organisasi kepada publiknya demi tercapainya suatu citra positif bagi kedua belah pihak.

\section{Peran Hubungan Masyarakat di Perguruan Tinggi}

Peran hubungan masyarakat secara konseptual dibedakan atas peran manajer dan peran teknisi. Peran manajer terdiri atas peran penasehat ahli,

21 Rudy Badrudin, 'STRATEGI PENGEMBANGAN PERGURUAN TINGGI SWASTA', Ekonomi Pembangunan, 9.2 (2008), 198-215. 
fasilitator proses pemecahan masalah, dan fasilitator komunikasi. Sedangkan peran teknisi yaitu teknisi komunikasi. ${ }^{22}$

Peran publik relation di universitas negeri sendiri cenderung bertindak sebagai communication technician dan hanya sedikit yang berperan sebagai communication facilitator. Hal seperti ini disebabkan karena organisasi dan tata kerjanya di Universitas negeri tidak memberikan kesempatan yang banyak untuk suatu peran. Jika ditelaah lebih lanjut, peran communication technician disebabkan oleh suatu lingkungan internal yang tidak banyak berubah-ubah (little change). Karena Peran communication facilitator disebabkan oleh suatu lingkungan internal yang banyak mengalami perubahan (much change). Kedua peran diatas tersebut kemungkinkan dapat dijalankan oleh humas dalam suatu kondisi eksternal yang rendah ancaman (low threat). ${ }^{23}$

Zulkarnain Nasution mengemukakan ada tiga alasan yang mendasari pentingnya peran Humas di Perguruan Tinggi:24 Pertama, Pengelolaan Perguruan Tinggi (rektor, pembantu rektor, dekan, pembantu dekan, senat di Universitas) sering menghasilkan suatu kebijakan yang terkait pada perguruan tingginya sehingga dapat dibutuhkan suatu bagian (dalam hal ini humas berperan) dalam hal ini yang secara terus-menerus dan terencana mensosialisasikan, yang memberi informasi kebijakan tersebut kepada masyarakat di dalam perguruan tinggi itu (mahasiswa, dosen, dan staf) dan masyarakat yang ada di luar perguruan tinggi (orang tua, mahasiswa, alumni, lembaga atau instansi lainnya) dan masyarakat luas.

Kedua, Persaingan yang dinamis dan sehat antar sesama perguruan tinggi di dalam negeri dan perguruan tinggi international dalam merebut minat dan calon mahasiswa, orang tua, atau masyarakat luas, yang membuat pimpinan perguruan tinggi dituntut untuk menyiapkan suatu bagian (dalam hal ini Humas yang beroeran) untuk mengelola suatu atas informasi yang jelas dan memberikan kesan citra positif.

Ketiga, Perkembangan suatu media masa cetak dan eletronik didaerahdaerah semakin meningkat, misalnya seperti surat kabar, radio swasta, dan televisi lokal di daerah-daerah, yang sudah selalu pasti mencari informasi yang aktual di perguruan tinggi, sebab dibutuhkannya bagian Humas untuk membina suatu hubungan yang harmonis dengan pihak pers tersebut. Tujuan agar informasi atau beritaberita yang positif dan membangun tentang perguruan tinggi selalu menjadi bahan informasi pers itu.

22 S.Ag Artis, 'STRATEGI KOMUNIKASI PUBLIC RELATIONS Oleh : Artis, S.Ag Abstraksi', Sosial Budaya, 8.2 (2011), 184-97.

23 S.Neni Yulianita Raden Putri Rahma, 'Makna Media Sosial Bagi Profesi Public Relations Perguruan Tinggi', Prosiding Hubungan Masyarakat, 2.1 (2016), 333-40.

24 T.E. Ardhoyo, 'PERAN DAN STRATEGI HUMAS( PUBLIC RELATIONS ) DALAM MEMPROMOSIKAN PRODUK PERUSAHAAN', IImiah WIDYA, 1.1 (2013), 15-21. 
Sebenarnya PR mempunyai suatu peran yang sangat besar dalam memajukan sebuah perguruan tinggi swasta, terutama dalam membangun persepsi yang positif tentang perguruan tinggi swasta tersebut dan menunjukkan kepada masyarakat bahwa perguruan tinggi swasta yang diwakili oleh PR itu berbeda dengan perguruan tinggi swasta lainnya. Seperti yang juga dikatakan oleh John E. Marston Public Relations ialah suatu seni untuk membuat perusahaan anda semua disukai dan dihormati oleh para karyawan, konsumen serta para penyalurnya anda. 25

Peran humas dalam sebuah lembaga atau organisasi ini sangat penting, karena itu disetiap lembaga membutuhkan kinerja seorang humas untuk membantu jalannya program kerja, dan humas juga dapat mempertahankan citra suatu lembaga tersebut, sehingga suatu lembaga itu dapat di kenal dan di percaya publik dengan strategi humas. Seorang humas itu adalah jembatan atau jalan pertama dari sebuah image yang terbentuk dimasyarakat pada suatu lembaga tertentu, seperti yang dilakukan oleh humas unitri dalam mempertahankan citranya dengan melakukan branding, bulding dan hubungan internal dan eksternal kepada publik, humas Unitri itu selalu mementingkan kepentingan publik yang selalu menampung aspirasi mahasiswa Unitri. ${ }^{26}$

\section{Jaringan Komunikasi dan Network Humas di Perguruan Tinggi}

Komunikasi adalah sebuah tindakan untuk berbagi informasi atau gagasan dan pendapat dari setiap partisip komunikasi yang telah terlibat didalamnya guna mencapai kesamaan makna. Tindakan komunikasi tersebut dapat dilakukan dalam beragam-ragam konteks, antara lain ialah dalam suatu lingkup organisasi (organizational communication). Dalam Al-Qur'an itu sendiri telah dijelaskan tentang pentingnya suatu komunikasi dalam organisasi terutama ketika mengambil suatu keputusan dalam setiap permasalahan yang ada, yang bisa dilakukan melalui musyawarah. ${ }^{27}$ Seperti firman Allah dalam Q.S. Asy-Syuura/42:38 yang berbunyi:
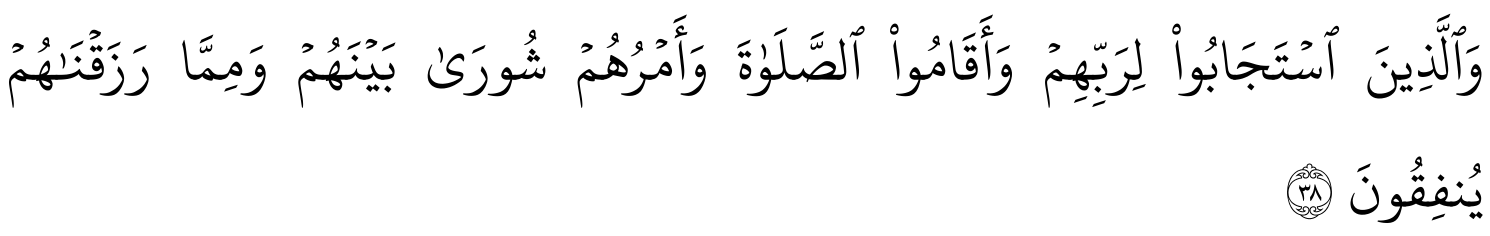

25 Theresia Intan Putri Hartiana, 'PENGGUNAAN E-MAGAZINE SEBAGAI BENTUKPUBLIC RELATIONS 2.0 BAGI HUMAS PERGURUAN TINGGI', Kajian Komunikasi, 2.1 (2014), 61-65.

26 Umar Farouk, 'PERAN PUBLIC RELATIONS DI PERGURUAN TINGGI NEGERI ( PTN ) DALAM ERA BADAN HUKUM PENDIDIKAN TINGGI', ILMU ADMINISTRASI DAN KEBIJAKAN BUBLIK, 6.1 (2009), 68-77.

27 Yanuar Luqman, 'Peran Dan Posisi Hubungan Masyarakat Sebagai Fungsi Manajemen Perguruan Tinggi Negeri Di Semarang', INTERAKSI, II.1 (2013), 1-10. 
Dan (bagi) orang yang menerima (mematuhi) seruan Tuhannya dan mendirikan shalat, sedang urusan mereka (diputuskan) dengan musyawarat antara mereka; dan mereka menafkahkan sebagian dari rezki yang Kami berikan kepada mereka.

Dalam komunikasi iniyang menjadi pusat perhatian (central point) adalah persoalan informasi yang dikelola dan disebarluaskan. Informasi inilah yang sesungguhnya akandikomunikasikan ke segenap publik dari organisasi yang bersangkutan. Pace \& Faules menyebutkan ada beberapa model proses transfer informasi dalam komunikasi organisasi. Model yang dominan muncul adalah bottom-up, top-down, horisontal, dan lintas saluran. Keempat model tersebut dapatberlaku bagi setiapkomunikasi internal dalam suatu perusahaan. 28

Networking merupakan suatujembatanpenghubung antara dunia pendidikan juga duniaindustri dan juga masyarakat sehingga networking sangat berperanpenting dalam lembaga pendidikan. ${ }^{29}$

Holtz, menyatakan kebanyakan aktivitas Public Relations (PR) dalam suatuinternet masih terbatas pada penggunaan media satu arah, dandari atas ke bawah untuk penerbitan informasi yang masih menggunakan formula komunikasi media masa yang tradisional.Dan ditambah lagi banyak perusahaan yang belum mengadopsi internet sebagai media PR atau di suatu perusahaan. ${ }^{30}$

Dengan hadirnya internet yang digunakan oleh begitu banyak orang, internetjuga bisa dimanfaatkan bagi para profesi Public Relations dalam menjalani aktivitasnya. Untuk menjalankan aktivitas Public Relations di media sosial, diperlukan kemampuan untuk berkomunikasi sehingga kepercayaan publik dapat diciptakanmelalui media sosial dan menghadirkan hubungan yang saling menguntungkan. ${ }^{31}$

\section{Peran Humas Dalam Pengembangan Pendidikan Tinggi}

Program dalamsuatupengembangan Humas harus pro aktif dan mampu mengantisipasikan perubahan-perubahan yang ada atau terjadi dengan cepat, baik di bidang teknologi, informasi, ekonomi, hukum maupun politik internasional dan nasional. Sentral Humas bertujuan yang hendak dicapai secara strategis, tidak hanya berfungsi sebagai "peta” yang menunjukkan arah lokasi, melainkan juga menunjukkan "bagaimana" operasional atau konsep dan strategi komunikasinya. Strategi dalam suatukomunikasi Humas merupakan satuperpaduan antara communication planning (perencanaan komunikasi) dan management

\footnotetext{
28Hartiana, "PENGGUNAAN E-MAGAZINE SEBAGAI BENTUKPUBLIC RELATIONS 2.0 BAGI HUMAS PERGURUAN TINGGI."

${ }^{29}$ Ardhoyo, "PERAN DAN STRATEGI HUMAS( PUBLIC RELATIONS ) DALAM MEMPROMOSIKAN PRODUK PERUSAHAAN.”

30Tamher and Hm, "PASAR INPRES KOTA TUAL The Roles of Public Relation in Crisis Management of the Tradisional Market Tual City Post Fire."

${ }^{31}$ Rianti, "KAJIAN YURIDIS TENTANG KEBERADAAN PERGURUAN TINGGI NEGERI BADAN HUKUM MILIK NEGARA DALAM UNDANG-UNDANG SISTEM PENDIDIKAN NASIONAL Rianti."
} 
communication (komunikasi manajemen). Tujuan sentral Public Relations iniadalah mengacu kepada kepentingan pencapaian sasaran (target) tersendiri atau tujuan untuk menciptakan suatu citra dan reputasi postitif pada suatu lembaga. Pembentukan, atau pemeliharaan dan peningkatan citra dan reputasi positif harus didukung oleh kebijakan dan komitmen pimpinan puncak. Kemampuan buntuk erkomunikasi, baik melalui lisan maupun tulisan adalah salah satu penyampaian media pesan, ide, dan gagasan program kerja, dan sekaligus membentuk opini atau menguasai suatu pendapat umum sesuai dengan yang diinginkan komunikator. ${ }^{32}$

Di dalam konteks ini memahami peran PR di perguruann Tinggi, maka dibutuhkan suatu pemahaman terhadap karakteristik perguruan tinggi. Adapun misi yang adadi perguruan tinggi berpijak pada kerangka tiga pilar (Tri Dharma Perguruan Tinggi), yaitu pendidikan, ataupenelitian dan pengabdian pada masyarakat. ${ }^{33}$

Bagi perguruan tinggi terdapat sebuah proses besar dalamkehidupannya, berupa proses menghasilkan ilmu secara utuh yang mengandung kebenaran, sehingga menghasilkan pakar (scientist scholar) yang berprofesi dan berbudaya melalui proses pembelajaran. Dengan berbasis pada gambaran proses tersebut, apabila dikaitkan dengan globalisasi ekonomi dunia, maka dibutuhkan paradigma baru dalam pengelolaan perguruan tinggi. Tentunya dengan tetap berpijak pada tiga pilar utama pendidikan tinggi tersebut yaitu pengajaran, penelitian dan pengabdian.

Di dalam bukunya Al Rise mengatakan 'The Rise of PR' untuk menunjukkan fenomena PR pada saat ini. Satu hal yang masuk pada nalar karena kehadiran PR yang sangat dibutuhkan disetiap organisasi dan institusi pada saat ini, tidak terkecuali didalam suatu dunia pendidikan tinggi, terlebih ketika Otonomi Perguruan Tinggi semakin ketat kedepannya yang akan diterapkan disetiap Perguruan Tinggi di Negara ini. Mau tidak mau, disetiap Perguruan Tinggi sudahsaling berlomba-lomba untuk menunjukkan siapa dirinya supaya tetap survive di tengah persaingan yang ada. ${ }^{34}$

\section{KESIMPULAN}

Pendidikan merupakan suatu aspek yang sangat penting dari pelaksanaan hak-hak asasi manusia, penyelenggaraan hak tersebut dilakukan setiap negara

32Soetjipto et al., "OTONOMI DAN TATA KELOLA PERGURUAN TINGGI NEGERI Studi Kasus Di Universitas Indonesia , Universitas Negeri Jakarta , Dan Universitas Islam Negeri Syarif Hidayatullah Case Studies in the University of Indonesia , the Jakarta State University, and the Syari."

33Nur Ahid, "Problem Pengelolaan Madrasah Aliyah Dan Solusinya," ISLAMICA 4, no. 2 (2010): 336-53.

${ }^{34}$ Farouk, "PERAN PUBLIC RELATIONS DI PERGURUAN TINGGI NEGERI ( PTN ) DALAM ERA BADAN HUKUM PENDIDIKAN." 
demi mencapai semua cita-cita nasional dan tujuan untuk negara yang bersangkutan.

Pentingnya menerapkan strategi public relations inidalam memasarkan Perguruan Tinggi disetiap Lembaga yang membutuhkan kinerja seorang humas untuk membantu jalannya suatu program kerja, dan juga humas dapat mempertahankan citra suatu lembaga di lembaga tersebut, sehingga suatu lembaga itu dapat di kenal dan di percaya publik dengan strategi humas. Seorang humas adalah jembatan atau jalan pertama dari sebuah image yang terbentuk dimasyarakat pada lembaga tertentu.

\section{DAFTAR PUSTAKA}

Ahid, Nur. "Problem Pengelolaan Madrasah Aliyah Dan Solusinya." ISLAMICA 4, no. 2 (2010): 336-53.

Anwar, Rofiq. "PERAN PRAKTISI PUBLIC RELATIONS DALAM ORGANISASI DI YOGYAKARTA." AN-NIDA 7, no. 1 (2015): 46-55.

Ardhoyo, T.E. "PERAN DAN STRATEGI HUMAS( PUBLIC RELATIONS ) DALAM MEMPROMOSIKAN PRODUK PERUSAHAAN." IImiah WIDYA 1, no. 1 (2013): 15-21.

Ardianto, Elvinaro. "Public Relations on the Net :" Mediator 2, no. 1 (2001): 11-19.

Artis, S.Ag. "STRATEGI KOMUNIKASI PUBLIC RELATIONS Oleh : Artis, S.Ag Abstraksi." Sosial Budaya 8, no. 2 (2011): 184-97.

Badrudin, Rudy. "STRATEGI PENGEMBANGAN PERGURUAN TINGGI SWASTA." Ekonomi Pembangunan 9, no. 2 (2008): 198-215.

Baharun, Hasan. "DESENTRALISASI DAN IMPLIKASINYA TERHADAP PENGEMBANGAN SISTEM PENDIDIKAN ISLAM." Jurnal At-Tajdid 1, no. 2 (2012).

Baharun, Hasan. “Manajemen Kinerja Dalam Meningkatkan Competitive Advantage Pada Lembaga Pendidikan Islam." At-Tajdid: Jurnal IImu Tarbiyah 5, no. 2 (2016): 243-62.

Baharun, Hasan. "PENDIDIKAN ANAK DALAM KELUARGA; TELAAH EPISTEMOLOGIS.” Pedagogik 3, no. 2 (2016): 96-107.

Baharun, Hasan. Pengembangan Kurikulum: Teori Dan Praktik (Konsep, Prinsip, Model, Pendekatan Dan Langkah-Langkah Pengembangan Kurikulum PAl). Yogyakarta: Cantrik Pustaka, 2017.

Baharun, Hasan, and Robiatul Awwaliyah. "Pendidikan Multikultural Dalam Menanggulangi Narasi Islamisme Di Indonesia." Jurnal Pendidikan Agama Islam (Journal of Islamic Education Studies) 5, no. 2 (2017): 224-43. 
Darmastuti, Lina Sinatra dan Ririn. "KAJIAN PERAN PUBLIC RELATIONS DALAM MENINGKATKAN CITRA PERGURUAN TINGGI SWASTA DI JAWA TENGAH." IImiah SCRIPTURA 2, no. 2 (2008): 95-105.

Farouk, Umar. “PERAN PUBLIC RELATIONS DI PERGURUAN TINGGI NEGERI ( PTN ) DALAM ERA BADAN HUKUM PENDIDIKAN." Jurnal Ilmu Administrasi Dan Kebijakan Publik 6, no. 1 (2009): 68-77.

Fathoni, M Kholid. "Badan Hukum Di Langit Pendidikan ( Studi Evaluasi Kebutuhan Satuan Pendidikan )." Pendidikan Dan Kebudayaan 17, no. 3 (2011): 299305.

Fauzi, Ahmad. "Pengembangan Human Relation Perspektif Nilai-Nilai Al-Qur'an." Mutawatir UIN Sunan Ampel Surabaya 1, no. 2 (2015): 168-79.

Hartiana, Theresia Intan Putri. "PENGGUNAAN E-MAGAZINE SEBAGAI BENTUKPUBLIC RELATIONS 2.0 BAGI HUMAS PERGURUAN TINGGI." Kajian Komunikasi 2, no. 1 (2014): 61-65.

İbrahim, Instr, and Serkan Ödemiş. "AN EXPLORATORY STUDY ON UNIVERSITY AUTONOMY: A COMPARISON OF TURKEY AND SOME EUROPEAN UNION COUNTRIES." OF EDUCATION AND INSTRUCTIONAL STUDIES IN THE WORLD 6, no. August (2016): 79-90.

Ishak, Aswad. "Peran Public Relations Dalam Komunikasi Organisasi." Jurnal Komunikasi 1 (2012).

Luqman, Yanuar. "Peran Dan Posisi Hubungan Masyarakat Sebagai Fungsi Manajemen Perguruan Tinggi Negeri Di Semarang." INTERAKSI II, no. 1 (2013): 1-10.

Mundiri, Akmal. "Organizational Culture Base On Total Quality Management In Islamic Educational Institution." ADRI International Journal Of Islamic Studies and Social Sciences 1, no. 1 (2017): 1-11.

Mundiri, Akmal. "STRATEGI LEMBAGA PENDIDIKAN ISLAM DALAM MEMBANGUN BRANDING IMAGE." Pedagogik 3, no. 2 (2016): 58-72.

Nurcahyani, Novi Arista. "Pelaksanaan Hubungan Masyarakat Dalam Membangun Networking Di SMK Negeri 1 Surabaya” 1, no. 1 (2015): 1-11.

Pendidikan, D I Lembaga, and Stie Trisakti. “Manajemen Humas (Public Relations) Di Lembaga Pendidikan." Media Bisnis, n.d., 1-7.

Raden Putri Rahma, S.Neni Yulianita. “Makna Media Sosial Bagi Profesi Public Relations Perguruan Tinggi.” Prosiding Hubungan Masyarakat 2, no. 1 (2016): 333-40.

Rianti. "KAJIAN YURIDIS TENTANG KEBERADAAN PERGURUAN TINGGI NEGERI BADAN HUKUM MILIK NEGARA DALAM UNDANG-UNDANG SISTEM PENDIDIKAN NASIONAL Rianti." IImu Hukum 7, no. 13 (2011): 1-10. 
Rini, Kurnia Setiyo, Sugeng Rusmiwari, Herru Prasetya Widodo, Program Studi, Ilmu Komunikasi, and Universitas Tribhuwana Tunggadewi. "Peran Humas Dalam Meningkatkan Citra Universitas Tribhuwana Tunggadewi." IImu Sosial Dan IImu Politik 6, no. 1 (2017): 34-37.

Soetjipto, Ani, Francisca Ery Seda, Ida Ruwaid Noor, Sri Budi, Eko Wardani, and Natalia Soebagjo. “OTONOMI DAN TATA KELOLA PERGURUAN TINGGI NEGERI Studi Kasus Di Universitas Indonesia, Universitas Negeri Jakarta, Dan Universitas Islam Negeri Syarif Hidayatullah Case Studies in the University of Indonesia , the Jakarta State University , and the Syari." Masyarakat \& Budaya 16, no. 2 (2014): 293-304.

Sulistyaningtyas, Ike Devi. "Peran Strategis Public Relations Di Perguruan Tinggi." IImu Komunikasi 4, no. 2 (2007): 131-44.

Tamher, Ratna Sari, and M Najib Hm. "PASAR INPRES KOTA TUAL The Roles of Public Relation in Crisis Management of the Tradisional Market Tual City Post Fire." Komunikasi KAREBA 1, no. 3 (2011): 271-82.

Wijaya, Ida Suryani. "Dinamika Komunikasi Organisasi Di Perguruan Tinggi." Dakwah Tabligh 14, no. 2 (2013): 203-15. 